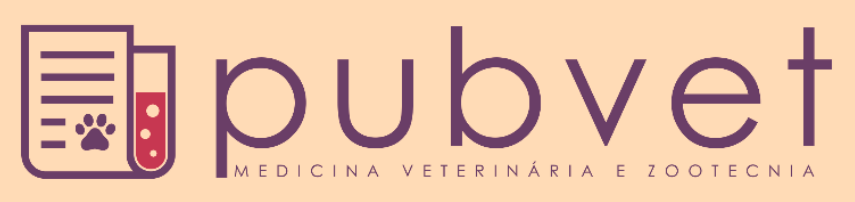

https://doi.org/10.31533/pubvet.v13n5a334.1-6

\title{
Metodologia ativa no treino de sutura: o uso do EVA na construção de maquete de sutura artesanal
}

\author{
Gustavo Duarte de Oliveira ${ }^{1 \oplus}$, Vanessa Pavesi de Faria ${ }^{2 \oplus}$ \\ ${ }^{I}$ Especialista /UEG. Pesquisador CAPES/UEG - GPEFDL. Graduando em Medicina Veterinária pela Universidade Montes Belos, \\ Pesquisador Voluntário do Grupo de Iniciação Científica em Veterinária. Pesquisa do uso de Metodologias Ativas em Educação \\ ${ }^{2}$ Mestre com Bolsa Fapesp pelo Departamento de Patologia Animal da Faculdade de Ciências Agrárias e Veterinárias - FCAV/Unesp, Jaboticabal, \\ exercendo atividades de pesquisa junto ao Laboratório de Farmacologia e Toxicologia Animal da UNICASTELO, participando do Group of Animal \\ Pharmacology (GAP). Atualmente docente e coordenadora do curso de Bacharelado em Medicina Veterinária da Universidade Montes Belos \\ * Autor para correspondência, E-mail: gustavo duartemusica@hotmail.com
}

Resumo. Este artigo tem o objetivo de ilustrar a prática da metodologia ativa em educação na medicina veterinária. A apresentação de um modelo artesanal de baixo custo e viável para o aprimoramento da técnica de sutura para cirurgiões médicos veterinários em formação. Pesquisa realizada na Universidade Montes Belos (UniMB) - São Luís de Montes Belos, Goiás - na graduação em Medicina Veterinária. Esta técnica de estudos e aperfeiçoamento em sutura é uma continuidade científica da pesquisa do uso de Metodologia Científica e como tal ferramenta educacional aprimora e molda um profissional com maior qualificação e desenvoltura científica.

Palavras-chave: EVA, metodologia ativa, sutura

\section{Active learning methodology in suture training: the use of EVA in the construction of craft suture model}

Abstract. This article aims to illustrate the practice of the active methodology learning in veterinary medicine education. The presentation of a low cost and feasible handmade model for the improvement of the suture technique for training veterinary surgeons. Research carried out at the Montes Belos University (UniMB) - São Luís de Montes Belos, Goiás - at the undergraduate degree in Veterinary Medicine. This technique of suture studies and improvement is a scientific continuity of the research of the use of Scientific Methodology and how such educational tool improves and molds a professional with greater qualification and scientific ability.

Keywords: EVA, active learning methodology, suture

\section{Metodología activa en el entrenamiento de sutura: el uso del EVA en la construcción de maqueta de sutura artesanal}

Resumen. Este artículo tiene el objetivo de ilustrar la práctica de la metodología activa en educación en la medicina veterinaria. La presentación de un modelo artesanal de bajo costo y viable para el perfeccionamiento de la técnica de sutura para cirujanos médicos veterinarios en formación. Investigación realizada en la Universidad Montes Belos (UniMB) - São Luís de Montes Belos, Goiás - en la graduación en Medicina Veterinaria. Esta técnica de estudios y perfeccionamiento en sutura es una continuidad científica de la investigación del uso de Metodología Científica y como tal herramienta educativa perfecciona y moldea un profesional con mayor calificación y desenvoltura científica.

Palabras clave: EVA, metodología activa, sutura 


\section{Introdução}

Metodologia ativa é uma ferramenta educacional emergente que apresenta suas aplicações educacionais a protagonizar o aluno em formação, ou seja, no sistema de ensino/aprendizagem terá o acadêmico como papel ativo em sua formação e capacitação profissional (Diesel et al., 2017). É possível inferir que, a prática desse tipo de metodologias em sala de aula pode favorecer a autonomia, despertar a curiosidade, estimular a iniciativa de resolução de problemas e decisões tanto individuais quanto coletivas (Borges \& Alencar, 2014).

O professor, mediador e a instituição de ensino orientam e direcionam o graduando a desenvolver sua independência científica. É preciso integrar o acadêmico em formação na atmosfera de ensinoaprendizagem advindo das atividades essenciais da prática social e em contextos como recurso didático na formação crítica e reflexiva do aluno universitário (Borges \& Alencar, 2014). A integração do mesmo no contexto em pesquisa e extensão, aprimorando e forjando o espírito científico ao ponto de fazer com que os próprios agentes em formação (acadêmicos de graduação) busquem o seu aperfeiçoamento como aquisição de conhecimento além da sala de aula (Santos et al., 2017).

A Metodologia Ativa (MA) tem uma concepção de educação crítico-reflexiva com base em estímulo no processo ensino-aprendizagem, resultando em envolvimento por parte do educando na busca pelo conhecimento. Dentro do conceito de metodologia ativa, existe o método a partir da construção de uma situação problema (SP), a qual proporciona uma reflexão crítica; mobiliza o educando para buscar o conhecimento, a fim de solucionar a SP; ajuda na reflexão e a proposição de soluções mais adequadas e corretas. As concepções teóricas e metodológicas da MA convergem com a Metodologia da Problematização (MP) (Macedo et al., 2018). Tal ferramenta educacional trabalha em duas frentes pedagógicas: PBL e Grupos Operativos (Diesel et al., 2017).

PBL - Problem Based Learning - Aprendizagem Baseada em Problemas, ou simplesmente Problematizações é uma frente pedagógica que instiga a pesquisa e a busca de soluções para um problema apresentado. Grupos Operativos é a integração de discussões e apresentações discursivas textuais ou verbais dos alunos referente a um assunto.

\section{Objetivo}

Caracteriza-se como objetivo principal deste artigo a prática do uso de Metodologias Ativas no ensino de curso de bacharelado como o de Medicina Veterinária nas disciplinas de prática cirúrgica onde o cirurgião em formação deve aprimorar sua prática de sutura. Enfatizar a capacidade e as habilidades do acadêmico em se tornar independente e forjar a sua educação como papel ativo, formação teórica e capacitação para o mercado de trabalho e no campo da pesquisa.

\section{Resultados e discussão}

A prática de sutura é uma técnica dentro da formação cirúrgica que depende do desenvolvimento pessoal do cirurgião em aplicar uma força adequada ao fio sem gerar a mínima reação tecidual (Matera, 2008; Medeiros et al., 2017; Nelson \& Couto, 2015). A sutura para o cirurgião é como a habilidade de desenho para o pintor e a precisão e segurança da costura para o costureiro (Barros et al., 2011). O cirurgião em formação precisa desenvolver sua técnica, precisão de tensão no nó cirúrgico, precisão de força para não romper o fio agulhado e desenvolver uma perda de tecido vivo (Medeiros et al., 2017). Portanto, o que é sutura? Em resposta, sutura é uma "costura", visto que, foi preciso incisionar uma área tecidual para a realização da cirurgia. Ou seja, ocorre a aproximação de tecidos antes separados pelo bisturi por intermédio de utensílios cirúrgicos.

Toda sutura causa três efeitos de maior ou menor efeito em sua aplicação em tecidos vivos: efeito síntese, efeito hemostático e recobrimento (Barros et al., 2011; Medeiros et al., 2017). O efeito síntese é reconhecido por aproximar tecidos, a tensão da sutura terá o efeito de propiciar a cicatrização primária da ferida. Após esta primeira ação, ocorrerá o recobrimento. O recobrimento é a cobertura das estruturas em planos anatômicos imediatamente abaixo da síntese. E por final do processo, há o efeito hemostático da sutura. Em consequência da tensão gerada pelos pontos, da aproximação dos tecidos e do recobrimento dos planos (Barros et al., 2011; Medeiros et al., 2017). Os efeitos síntese, recobrimento e hemostático corrobora para o sucesso no pós-operatório. Como o próprio autor discute, "a interação 
apropriada desses efeitos, resultando em tratamento adequado das feridas, dependerá do material a ser utilizado e de correta técnica cirúrgica a ser empregada".

Pode-se esquematizar o seguinte quadro analítico para o desenvolvimento de suturas conforme demonstrado abaixo:

Quadro 1. Durabilidade, planos e bordas de suturas

\begin{tabular}{|lll|}
\hline \multirow{2}{*}{ Durabilidade } & a) & Absorvíveis \\
& b) & Não absorvíveis \\
Planos & a) & Contínuo \\
& b) & Separado/isolado \\
Bordas & a) & Inversão de bordas teciduais \\
& b) & Eversão de bordas teciduais \\
\hline
\end{tabular}

Segundo Medeiros et al. (2017), a classificação das suturas apresentada no esquema abaixo é abordada de maneira generalizada em relação aos fios de sutura onde foram acrescentados os nomes comerciais de alguns para melhor assimilação (Figura 1).


Figura 1. Demonstração dos tipos de suturas: absorvíveis e inabsorvíveis. Fonte: Medeiros et al. (2017) 


\section{A expectativa de sutura}

Ao ler a revisão realizada no Departamento de Cirurgia da Universidade Federal do Rio Grande do Norte (UFRN) é possível destacar alguns pontos que devem ser levados em consideração para o treino de sutura pelo acadêmico em formação, em relação ao fio, de acordo com Medeiros et al. (2017):

- Resistência adequada.

- Mínima reação tecidual.

- Não se degradar em produtos tóxicos.

- Não facilitar a infecção e permanecer estável na sua presença.

- Calibre e resistência constantes.

- Coeficiente de atrito adequado

- Capacidade de manter a resistência até quando necessária

- Velocidade de absorção não afetada pelos líquidos corporais

- Ser de fácil manuseio - nó fácil e firme

- Elasticidade adequada

- Não ser alterado com a esterilização

- Ter baixa capilaridade

- Não alergênico e não mutagênico

- Ser de baixo custo.

O cirurgião em treinamento precisa levar todos estes tópicos em consideração para manusear um fio sensível que gera um coeficiente de atrito significativo que pode garantir o desgaste tecidual e assim, perder margem de tecido vivo impedindo bordas necessárias para fechar concluindo a cirurgia. A segurança da sutura só é conquistada pelo desenvolvimento de uma técnica de execução pessoal mediante ao estilo de cada sutura já canonizada. A comprovação científica de um dito popular: "a prática leva a perfeição".

\section{A maquete de sutura artesanal}

Não é sempre que temos tecido vivo a disposição para o treinamento de suturas. Sem contar que o preço de órgãos permitidos para comercializados em açougues se torna inviável para a prática de estudos, visto que, o treino e estudos cirúrgicos devem ser contínuos e o tempo deteriora a peça anatômica adquirida. Portanto, como utilizar uma peça que não se deteriora com o tempo e possui uma grande facilidade para ser produzida, pois os materiais para a sua confecção são fáceis de ser encontrados e com preço viável?

A folha de $\mathrm{EVA}^{1}$ é um tipo de borracha não tóxica, por isso constantemente usada em trabalhos artesanais, que possui etil, vinil e acetato em sua composição. Bastante flexível, maleável e de durabilidade considerável.

\section{Materiais e métodos}

Para a criação da maquete artesanal, foram necessários: folhas de EVA (recomendado cor clara); Material para base (recomendado um material resistente como um pedaço de madeira, ou plástico denso); régua; canetas; tesoura e supercola.

$1^{\circ}$ Passo - corte a folha de EVA em pedaços com formatos quadriculados e retangulares;

$2^{\circ}$ Passo - com a ajuda da régua, trace uma reta na folha de EVA e com ajuda de uma tesoura, corte a linha reta traçada. Com uma régua e caneta, alcance uma média de 0,5 a $1 \mathrm{~cm}$ de borda da incisão feita

${ }^{1}$ EVA - Material de fácil acesso e compra em papelarias. Comumente usado em trabalhos pedagógicos no desenvolvimento de ensino aprendizagem com média de curto de dois reais $(\$ 2,00)$ por folha. 
anteriormente e trace pontilhados paralelos a primeira reta. Repita para o outro lado da incisão feita. Os pontos serão as marcações para as suturas.

$3^{\circ}$ Passo - Com um auxílio da supercola, cole a folha de EVA a uma base resistente (madeira ou plástico) para te dar equilíbrio durante o treino (Figura 2).
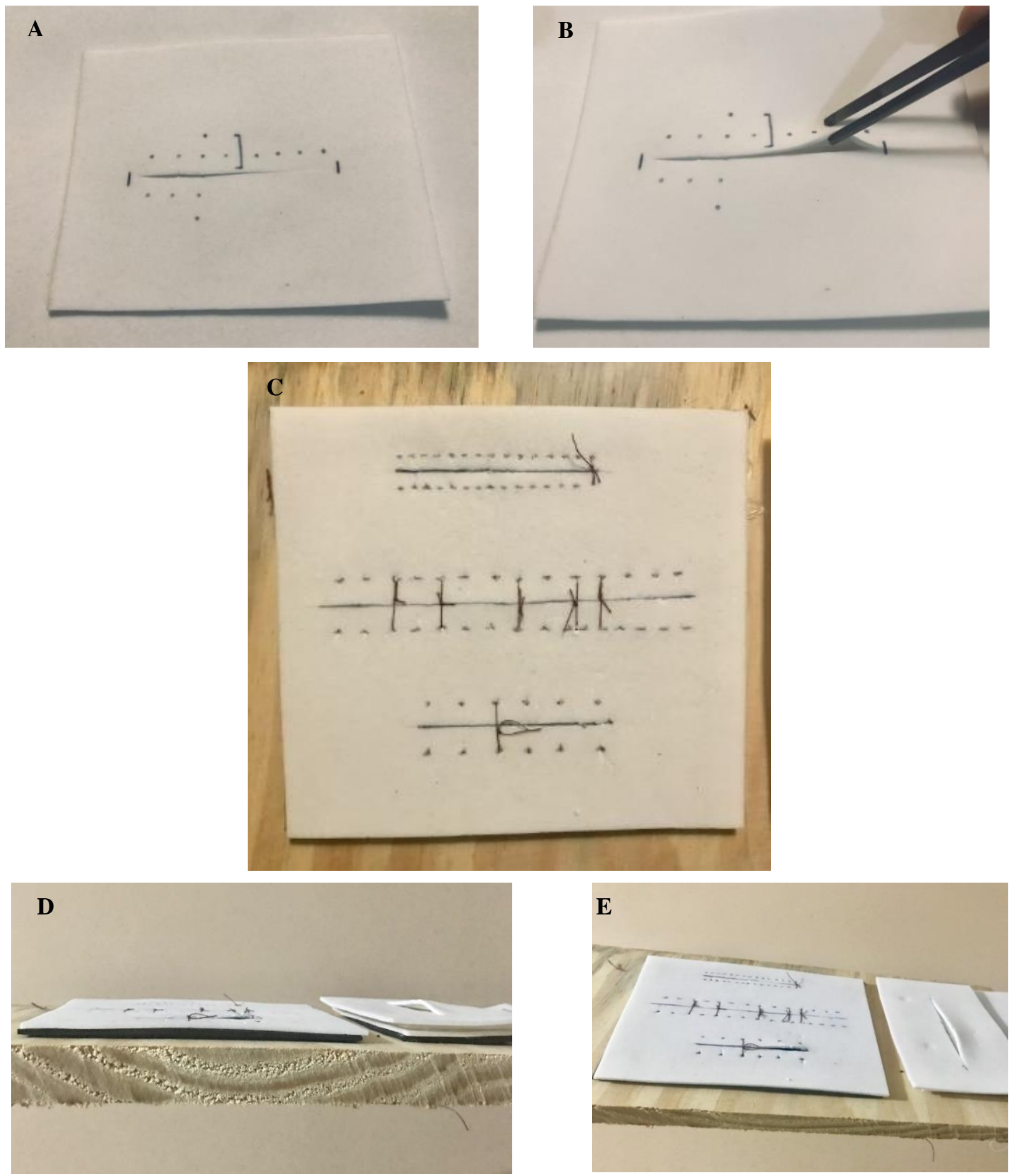

Figura 2. Maquete artesanal (A) Imagem frontal do EVA com marcações para a realização de suturas; (B)Visualização frontal/lateral do EVA para as suturas com a passagem do fio agulhado; $(\mathbf{C})$ Imagem frontal das suturas que podem ser realizadas com a maquete artesanal; (D) Visão lateral da maquete de sutura artesanal; (E) Visão frontal com inclinação para medial com exposição dos tipos de sutura simples isoladas para o treinamento. 


\section{Conclusão}

Apreende-se com a leitura deste artigo que, por intermédio da Metodologia Ativa, é possível desenvolver realidades educativas acessíveis para o estudo e aprimoramento de técnicas que são invasivas e de difícil acesso como o caso dos estudos de sutura. Isso se deve ao fato de ser complexo na prática diária em tecido vivo.

O uso de folhas de EVA aproxima o aluno em formação a uma realidade que ele irá encarar diariamente em centros cirúrgicos. Usando o material de fácil acesso, o aluno poderá praticar e desenvolver sua técnica pessoal de sutura.

\section{Referências bibliográficas}

Barros, M., Gorgal, R., Machado, A. P., Correia, A. \& Montenegro, N. (2011). Princípios básicos em cirúrgia: fios de sutura. Acta Med Port, 24(S4):1051-1056.

Borges, T. S. \& Alencar, G. (2014). Metodologias ativas na promoção da formação crítica do estudante: o uso das metodologias ativas como recurso didático na formação crítica do estudante do ensino superior. Cairu em Revista, 3(4):119-143.

Diesel, A., Baldez, A. L. S. \& Martins, S. N. (2017). Os princípios das metodologias ativas de ensino: uma abordagem teórica. Revista Thema, 14(1):268-288.

Macedo, K. D. S., Acosta, B. S., Silva, E. B., Souza, N. S., Beck, C. L. C. \& Silva, K. K. D. (2018). Metodologias ativas de aprendizagem: caminhos possíveis para inovação no ensino em saúde. Esc Anna Nery, 22(3):e20170435.

Matera, J. M. (2008). O ensino de cirurgia: da teoria à prática. Ciência Veterinária nos Trópicos, 1192101.

Medeiros, A. M., Araújo-Filho, I. \& Carvalho, M. D. F. (2017). Fios de sutura. Journal of Surgical and Clinical Research, 774-86.

Nelson, R. W. \& Couto, C. G. (2015). Medicina interna de pequenos animais. Amsterdan: Elsevier Editora.

Santos, L. R. O., Melo, R. \& Costa, J. J. (2017). A Metodologia da problematização no contexto da educação básica: possíveis caminhos para a formação de reeditores ambientais. Cadernos de Estudos e Pesquisa na Educação Básica, 3(1):257-274.

Recebido: 15 de abril, 2019.

Aprovado: 15 de maio, 2019.

Publicado: 6 de junho, 2019.

Licenciamento: Este artigo é publicado na modalidade Acesso Aberto sob a licença Creative Commons Atribuição 4.0 (CC-BY 4.0), a qual permite uso irrestrito, distribuição, reprodução em qualquer meio, desde que o autor e a fonte sejam devidamente creditados 